\title{
CREATIVE INDUSTRIES: CHALLENGES AND OPPORTUNITIES IN XR TECHNOLOGIES
}

\author{
Hana NOVAKOVA ${ }^{1 *}$, and Peter ŠTARCHOŇ ${ }^{1}$ \\ ${ }^{1}$ Tomas Bata University in Zlín, Faculty of Multimedia Communications, Univerzitní 2431, 76001 \\ Zlín, Czech Republic
}

\begin{abstract}
The paper aims to point out current challenges and opportunities in extended reality (XR) technologies that cover augmented, mixed and virtual reality (AR, MR, VR) within the frame of creative and related industries and current technological progress particularly based on the results of primary research. While the XR technologies struggle with limitations of the proper research on one side, multiple research projects including this one, have shown significant acceptance and potential of the XR technologies, especially in the ongoing digital era accelerated by the COVID-19 situation. The research presented in this paper was held with the small groups of artists in France who had opportunity to test the augmented reality mobile application on artworks from various artists. This and other cited research projects show that the acceptance rate of the XR technologies by the informed audience strongly predominates over its penetration in such population which can be interpreted as significant market opportunity. This milieu has strong impact on the democratization of the XR industry in the recent years with substantial investments by business sector. Meanwhile these technologies have become powerful enough to raise serious concern of their impact on ethical issues, social distancing and other related topics.
\end{abstract}

\section{Introduction}

From the low penetration rate of the extended reality technologies, it might seem that there is not big chance for the XR to become successful technology with all the current challenges it faces: especially technical, financial and ethical. While the economic impact of VR alone was supposed to achieve approx. 15bn USD, by the year of 2020 according to Adaola [1], some users feel repulsion to the digital worlds or heavy headsets, addiction issues or social distancing. However, during the research conducted in France with the university art students about their attitudes to augmented reality (AR) and another research of the perception of virtual reality (VR) by children and their parents, the obtained results show the opposite. The aim of this article is to highlight the current challenges and

\footnotetext{
* Corresponding author: h1_novakova@utb.cz
} 
opportunities in XR and to put the results from the conducted research projects in broader context of the current situation on the XR market and technological progress.

Technological development plays crucial and positive role in the XR hardware and software democratization, both on the developers' and users' side. Not only the upcoming $5 \mathrm{G}$ that allows users to transfer big data instantly, but also each new successful XR content means a huge technological leap. According to Zhu [2] "in the future of 5G communication and IoT (Internet of Things) applications under human-machine interaction will drastically affect the lifestyle of human in the social networking aspect, and this kind of device can improve the intelligence of machines based on the big data acquired from AI techniques." For example, in VR gaming the high-end users already benefit from Hife-Life: Alyx, while the massive spread of Czech-made game Beat-Saber (bought by Facebook) has demonstrated there is a serious increase of the number of the new users which makes the industry more attractive for investments, and development. However, Lee [3] argues that large number of current VR application domains suffer from software issues since no single system supports satisfactorily all the aspects of creation of a virtual reality application.

Currently the market is awaiting the advanced holo-technologies by Microsoft for experts and developers, Apple Glasses for early-users and Facebook glasses for massive spread of the technology. Once the masses start using VR, that by then will be probably called extended realities (XR), the fancy light glasses combined with amazing and useful content become less expensive, even more users will be attracted. These new users will profit from better XR hardware and software which again would attract more investments, research and development. As the XR content and technologies become more accessible financially and technologically for wider groups of people the democratization of the XR becomes reality. Another argument for the importance of XR are the new paradigms brought by the pandemic. More than year lasting pandemic with repetitive lockdowns has changed the way mass audiences consume education, entertainment and express themselves in arts, humanities, business, science etc. There is a significant decline from the massive public experiences (for example concerts or movie-theatres for hundreds of present visitors) in favor to the individually shared consumption. All this within the quote of Oculus evangelist Palmer Lucky:" Digital worlds were not made to separate people in their basements but to connect them through the new metaverses created by human imagination." According to Hain [4] the interdisciplinarity, synergistic effects, organized design process and educational strategies are the key principles for the protection of the local industrial heritage.

\section{Theoretical background / Literature review}

The digital worlds have experienced a long and dramatic progress from original cyberpunk ideas by William Gibson or Neal Stephenson to the most immersive experiences of nowadays. „Some recent studies by marketing scholars have proposed a framework for research in digital marketing where VR and AR, that is, XRs, are identified as critical digital technologies that will lead to new marketing opportunities,“ concludes in his study Alcañiz [5]. Gobiera [6] argues that the widely accepted model called „Milgram's Reality virtuality continuum" is already an outdated concept as the XR technologies are in service of the reality itself and calls in his paper for more proper research of these technologies: „Due to a shortage of investment, we are not using its full potential.“

According to Grizewski's [7] research conducted on VR marketing communication on 150 observations of respondents tested on VR presentation with Oculus Rift hardware, video 
and printed advertisements, the VR technology has significant and positive impact on all three communicated media: the acceptation of the offer, the VR technology and the presentation itself. Confronted with the Mine's [8] comparison of the historical virtual environments created in various US leading colleges and universities, the development of the interaction techniques has since the start compensated for the limitations of working in virtual world while simultaneously exploiting its power. This argument was later updated from the perspective of the narrative of the virtual worlds in the Ryan's [9] monography where she explains the trade-of among the interactivity and immersion in virtual environments. Javorik's [10] psychological analysis later demonstrated a strong link between immersion, affective responses, and positive user experience. Another study focused on the XR opportunities in tourism, states that tourism may not easily recover to pre-pandemic times. According to Lacka [11] and later confirmed by Kwok [12] "there are various ways how tourism enterprises can navigate the prohibitive travel climate, firstly for survival, and subsequently transform towards thriving in the post-pandemic new normal by exploiting XR as technological innovation.“

\section{Methodology}

Opposite to Munoz-Leiva [14] who started the first-ever longitudinal review of the state of art in merchandising research spreading into 60-year period, that provided holistic approach, this research on augmented reality (AR) was held two weeks in October 2020 in Aix-en-Provence, France with small groups of university art students with potential to capture the current creative industries trends. Prior to the study and based on the Cawood [15] and Fiala findings on AR. Each group of students was asked to read and sign an informed consent in an electronic form. The methodology consisted in three parts: Part 1 consisted of a workshop with advanced AR technologies in artworks from various authors. Part 2 was based on observation of the researchers and Part 3 on a semi-structured interview consisting of grading, answers from selected options and open answers of respondents recorded by the art students themselves through the application. The limitation of the research is mainly the number of respondents during pandemic, which was in total 21. This research is, when it is meaningful, supported by the data from another VR research on perception of children and parents based among others on the previous findings of analysis of human gestures in the 3D spaces by De Amicis and Soave [16] and also Guillaume [17] VR technological concepts combined with Lucas [18] This second research was held in September 2020 in Zlín, Czech Republic with 39 respondents, out of which 18 were parents and 21 children. Both research projects showed further areas of exploration and the authors plan to collect more data. As shown by Naz [19] lower quantity of participants as limitations are quite common in VR experiments as each participant of the research usually requires separate time due to the individual VR experience.

\section{Results}

The source of all the figures in this section are from the own research.

Figure 1 and 2 show the attitude of the French artist respondents towards the XR mobile technologies and their will to repeat the experience in the future to find out the acceptation rate of the technology. Only $19 \%$ of answers were neutral in the case of XR mobile applications. All of the other answers were positive. 

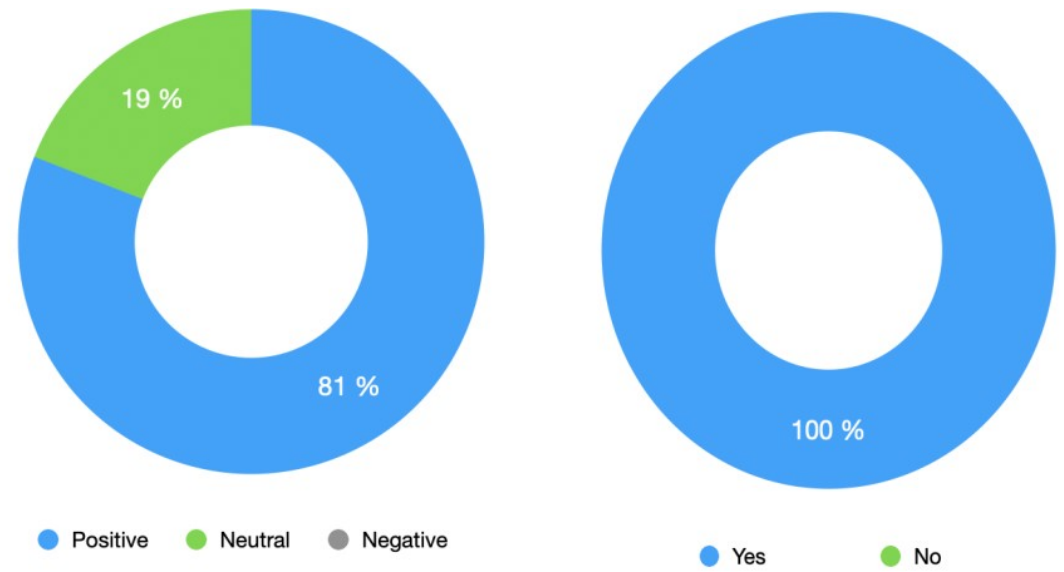

Fig. 1. Attitude towards XR mobile application. Fig. 2. Will to repeat the experience in the future.

Figure 3 and 4 show the ideal length of the AR experience according to the users: $43 \%$ of the experiences were supposed to last from 11 to $20 \mathrm{sec}$. and $33 \%$ below that time. No respondent wanted to hold the phone over 1 minute for the experience. The willingness to create AR projects among the potential art students and teachers was positive in $81 \%$.
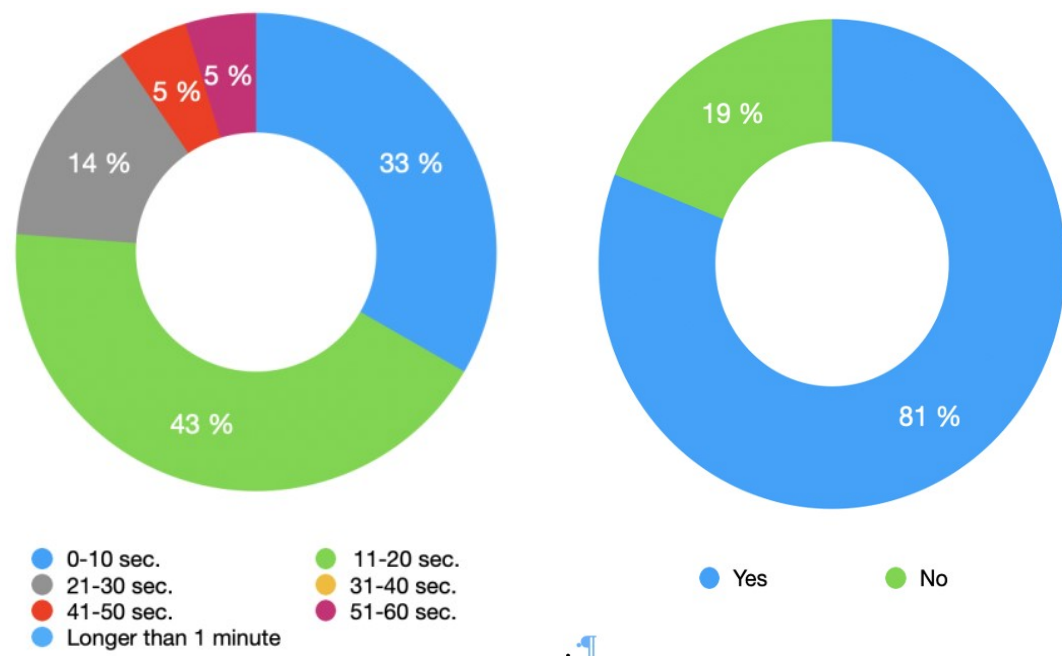

Fig. 3. Preferred length of AR mobile experience. Fig. 4. Would you use AR for your projects?

The following chart shows the best use for AR according to the respondents when $38 \%$ would use AR for 2D or 3D animation, almost one fifth for AR posters and one fifth of the respondents would bring new life for artworks. Next best use would be AR illustrations in the books (14\%), architecture and design $(5 \%)$ or additional information $(5 \%)$ 


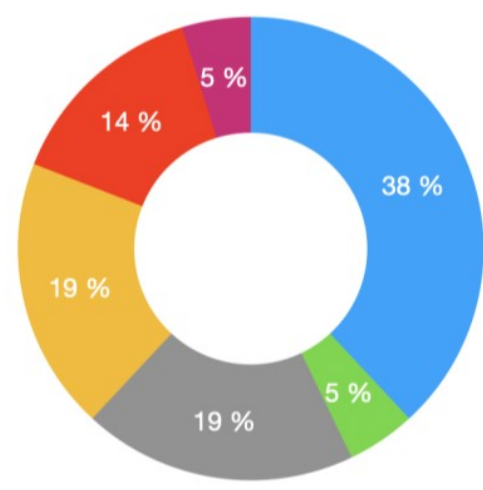

Animation 2D or 3D

Additional information

AR posters

New life for artworks

AR use of illustrations in the books

$\mathrm{AR}$ architecture and design

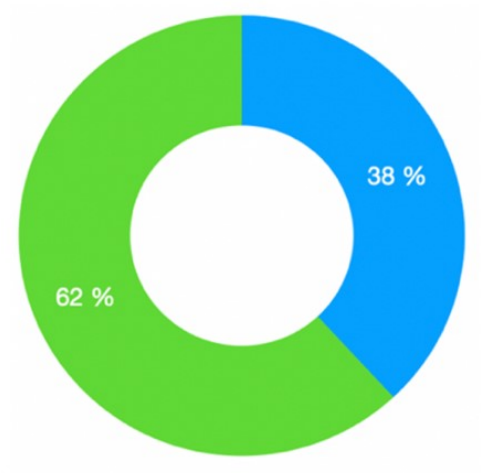

New user

Other answers

Fig. 5. The best use for AR in Arts. Fig. 6. New or experienced users?

The last four figures define $38 \%$ as new users and $62 \%$ respondents as not new to AR but not using it. $67 \%$ of the respondents as female and $33 \%$ as male.

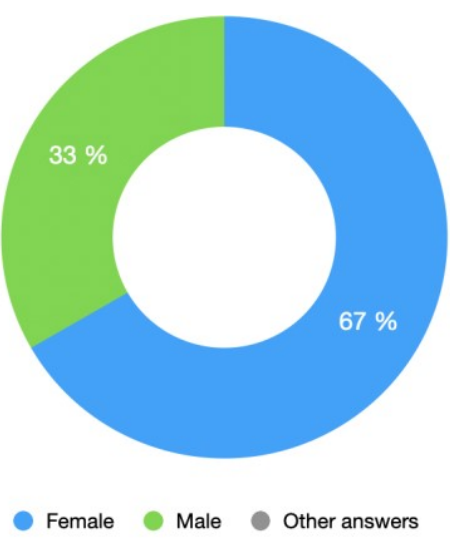

Fig. 7. Gender of the respondents.

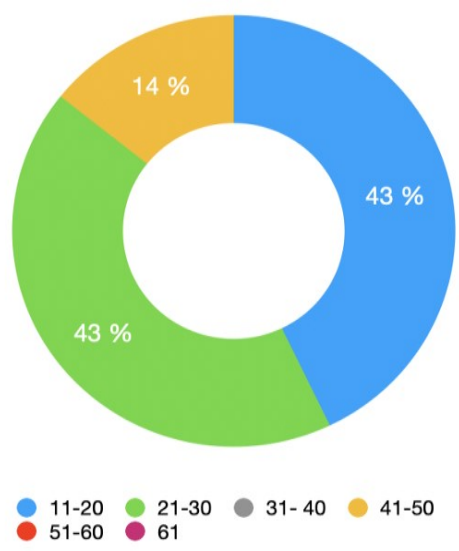

Fig. 8. Age of the respondents.

$43 \%$ of the respondents were 20 years old or younger, another $43 \%$ of the respondents were 21 to 30 years old and the time they have dedicated to arts vary from no answer to several decades.

The last Figure summarizes how many years did the respondents spend deicating their time to creation of varioius forms art from sculpture or painting to any form of modern digital or visual artsmand the answers show a great variety. 


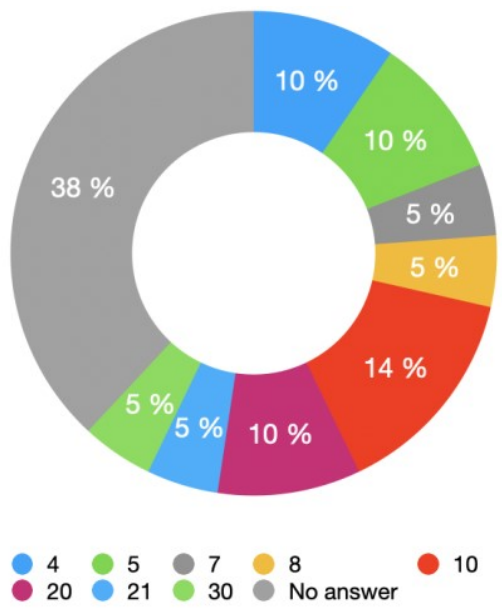

Fig. 9. How many years are you in Arts?

\section{Discussion and interpretations}

The attitude towards XR mobile applications during the research held in France among art students on AR (Fig. 1) was positive in $81 \%$ of the cases. There was no negative answer. About one fifth was neutral. The will of the respondents to repeat the XR experience (Fig. 2 ) in the future was $100 \%$. The high acceptation rate was probably among other reasons caused by previous workshop where the technology was tested by the respondents and they had opportunity to experiment with it. It is possible that the results would differ in the audiences that had no previous chance to try the experience. The positive acceptation rate was also obtained in another research held for children ( $100 \%$ will to repeat the experience) and their parents (96\% will to repeat the experience) in the Czech Republic where the VR software was tested on total of 39 respondents. Next questioning of the art students intended to find out how long mobile AR experience is the most popular (Fig. 3) and the results show that shorter is better. The interpretation of such results consists of the fact that people are usually not keen to hold their mobile devices in one stable and intact position for long time with one third of the respondents considered the time below 10 seconds is preferable. The figure 4 shows the $81 \%$ acceptance rate of the AR projects among the French artists from the point of view of creators. On the other hand, the current immersive VR experiences make sense in the length of about 10-12 min. depending on the immersive rate of the content and interactivity of the narrative. The best use of AR projects from the point of view of the artists is according to the art related respondents shown on chart on Figure 5. Moving objects or animation have higher acceptation rate than static pictures. The last four charts (Fig. 6, 7, 8 and 9) are about the respondents: There were more women than men among respondents, the artists were often new to the technology or haven't use it. Majority of the respondents $(86 \%)$ were aged under 30 years of age and the number of years they spent in arts varies from no answer to 4 up to 30 years.

\section{Conclusion}

The key findings of the conducted research projects show that the acceptation rate by various groups of population who had chance to experiment with the XR technologies are significantly high: from $81 \%$ to $100 \%$ depending on (1) the respondents (French art students capturing the latest trends, children or parents in the Czech Republic) and (2) the 
question asked (Would you like to repeat AR or VR experience in the future? Would you use AR technology for your projects?). At the same time the penetration rate of these technologies is rather low as the research shows and often new for the respondents. The creative industries and related fields are though experiencing unprecedented period of opportunities, combined with the factors predicted by Lévy [20] such as digitalization and upcoming 5G, rapid technological progress combined with as Carayannis [21] points out industry 5.0, society 5.0, transformation, blockchain, and the role of AI via the internet of things architectures and significant investments by the ICT companies in XR. The positive effects or externalities of XR are visible both, for the users and the producers and touch a wide range of activities based on creativity, digital worlds, knowledge or information: from advertising, architecture, design to gaming, software and publishing. Such era can be interpreted as new potential of the XR technologies as the cross-industry discipline. The optimistic conclusion for the developers is expected to arrive with amazing potential also for the users who can benefit from "More for Less" factor deriving from the democratization of the industry, thus more content for lower prices, more immersive experience with amazing data transfer and cloud computing in seconds or less. At the same time these technologies have become powerful enough to raise serious ethical, legal and social questions e.g. how to cope with the digital social distancing and other related topics. 


\section{References:}

1. T. Adaola, L. Páduaba, M. Foncesa, L. Agrellosc, Sousaa Luís Magalhãesd Emanuel Peresa, A rapid prototyping tool to produce $360^{\circ}$ video-based immersive experiences enhanced with virtual/multimedia elements, Procedia Computer Science, 138 Pages: 441-45 , Published: (2018)

2. M. Zhu, Z. Sun, Z. Q. Shi, T. He Huicong Liu, T. Chen, Chengkuo Lee, Hapticfeedback smart glove as a creative human-machine interface (HMI) for virtual/augmented reality applications, Science Advances - applied sciences and technologies, 6, DOI: 10.1126/sciadv. aaz8693, (May 2020)

3. S. H. Lee, S.H. Nam and J. Y. Kim, Analysis of a Quality Evaluation Model for VR Contents, International Journal of Grid and Distributed Computing, 11 pp.97-110 http://dx.doi.org/10.14257/ijgdc.2018.11.2.09, South Korea, (2018)

4. V. Hain, R. Löffler, V. Zajíček, Interdisciplinary Cooperation in the Virtual Presentation of Industrial Heritage Development, Procedia Engineering, 161, p. 20302035, ISSN 1877-7058, https://doi.org/10.1016/j.proeng.2016.08.798 (2016)

5. Alcañiz M, Bigné E and Guixeres J (2019) Virtual Reality in Marketing: A Framework, Review, and Research Agenda. Frontiers in Psychology 10, doi: 10.3389/fpsyg.2019.01530, (July 2019)

6. P. Gobiera; De Obiera Silva; About Reality: relations between museums and virtual reality, Virtual Creativity, 9, numbers 1\&2, Intellect Ltd. Article, DOI: https://doi.org/10.1386/vcr_00005_1 (2019)

7. F. Grudzewski, A. Marcin, G. Mazurek, K. Piotrowska, Virtual reality in marketing communication - the impact on the message, technology and offer perception empirical study, Economics and business review, 4, DOI: 10.18559/ebr.2018.3.4, (Jul 2018)

8. R, Mine, Mark, ISAAC: a meta-CAD system for virtual environments, Computer-aided design, 29, pp 547-553, Elsevier Science Ltd. 0010-4485/97, PII: 00104485(96)00095-4

9. M. L. Ryan, Narration as virtual reality: immersion and interactivity in literature and electronic media, Translation: Eva Karasová. Prague: Academia, Možné světy. ISBN 978-80-200-2507-4. Retreived (2020).

10. A. Javorik, Marder, B; Pizzetti, M; Warlop, L, Augmented self-The effects of virtual face augmentation on consumers' self-concept, Journal of Business research, 130, pages 170-178, DOI: 10.1016/j.jbusres.2021.03.026, (2021)

11. A. O. J. Kwok \& Sharon G. M. Koh (2020), COVID-19 and Extended Reality (XR), Current Issues in Tourism, 17, DOI: 10.1080/13683500.2020.1798896 (July 2020)

12. Lacka, E., Assessing the impact of full-fledged location-based augmented reality games on tourism destination visits. Current Issues in Tourism, 23, 345-357. https://doi.org/10.1080/13683500.2018.1514370, Google Scholar, (2020)

13. L. Buchholtz; Fine, Gary Alan; Wohl, Hannah Art markets in crisis: how personal bonds and market subcultures mediate the effects of COVID-19, American Journal of Cultural Sociology 8:462-476 https://doi.org/10.1057/s41290-020-00119-6, (2020) 
14. F. Munoz-Leiva, Mer Lopez, F. Liebana-Cabanillas, S. Moro, Past, present, and future research on self-service merchandising: a co-word and text mining approach. European Journal of Marketing, DOI: 10.1108/EJM-02-2019-0179, (2021)

15. S. Cawood; Fiala, Mark; Augmented Reality: A Practical Guide; Paperback: 328 pages; Publisher: Pragmatic Bookshelf; 1 ISBN-13: 978-1934356036, (Jan, 2008).

16. R. De Amicis; Soave, Marco; Analysis of Human Gestures in the 3D Space to Control Multimedia Interfaces, Fondazione Graphitech, Via alla Cascata 56/c, 38123 Povo (TN), Italy (2020)

17. P.M. Guillaume; Pascal Guitton, ed. Virtual reality: concepts and technologies. 2. Boca Raton, FL: CRC Press. ISBN 04-156-8471-4. (2011)

18. S. Lucas, Erin Pangilinan; Vasanth Mohan; (23 April 2019). Creating Augmented and Virtual Realities: Theory \& Practice for Next-Generation Spatial Computing, 300p., O'Reilly, ISBN-10: 1492044199. Retrieved in (2021)

19. A. Naz, R. Kopper, P. Ryan, Emotional Qualities of VR Space IEEE Virtual Reality (VR), March 18-22, Los Angeles, CA, USA 978-1-5090-6647-6/17 (2017)

20. P. Lévy; Cyberculture, Rapport au Conseil de l'Europe, Odile Jacob, ISBN 9782738105127, Retrieved in (2020)

21. E. Carayannis; K. Christodoulou; P. Christodoulou, S. Chatzichristofis; Z. Zinonos, Known Unknowns in an Era of Technological and Viral Disruptions-Implications for Theory, Policy, and Practice, Journal of the knowledge economy, DOI: 10.1007/s13132-020-00719-0, (Feb, 2021) 